\title{
Expression of endocrine genes in zebrafish larvae in response to environmental salinity
}

\author{
Kazuyuki Hoshijima and Shigehisa Hirose \\ Department of Biological Sciences, Tokyo Institute of Technology, 4259-B-19 Nagatsuta-cho, Midori-ku, Yokohama, Kanagawa 226-8501, Japan \\ (Requests for offprints should be addressed to S Hirose; Email: shirose@bio.titech.ac.jp)
}

\begin{abstract}
We tested the capability of the endocrine system in zebrafish to respond to environmental salinity challenges during larval stages. We reveal that the zebrafish larvae have a system in which several endocrine genes, including atrial natriuretic peptide (anp), renin, prolactin, growth hormone ( $g h)$ and parathyroid hormone 1 (pth1), respond at the transcription level to changes in environmental salinity and that the responses are gene specific. Both anp and renin are upregulated in larvae raised in dilute freshwater medium but are downregulated in concentrated medium. On the other hand, expression of
\end{abstract}

prolactin and $g h$ is strongly enhanced in the dilute medium, but shows little or no change under higher salinity conditions. Interestingly, PTH1 expression depends on $\mathrm{Ca}^{2+}$ concentration, as observed in mammals. Thus, taken together with the advantages of a model organism, including accessibility to genetic approaches, we propose that zebrafish larvae are useful for a comprehensive study of the regulatory mechanisms of the endocrine system in ionic and osmotic homeostasis.

Journal of Endocrinology (2007) 193, 481-491

\section{Introduction}

Maintenance of constant ionic and osmotic states in body fluid is essential for survival of vertebrates, although the homeostatic strategies differ according to the external environment. Terrestrial tetrapods, which are constantly threatened with desiccation, principally retain water and salt. On the other hand, in freshwater, where ion concentrations are extremely low, teleost fish have to actively take up ions from the environment, to compensate for loss of ions down the concentration gradient, and must excrete excess water taken up by osmosis (Greenwell et al. 2003, Kirschner 2004, Evans et al. 2005). In contrast, in seawater, where ionic and osmotic strength are higher than in the body, fish must excrete excess ions and absorb water.

As in mammals, the endocrine system plays a central role in such homeostatic regulation in fish (McCormick \& Bradshaw 2006). Many endocrine genes, including hormones and activating enzymes, have been identified in teleost fish and are known to function similar to mammalian genes with respect to ionic and osmotic homeostasis (McCormick 2001, Takei \& Loretz 2005). However, it is also evident that some genes are functionally diverged to adapt to the aquatic environment. For example, atrial natriuretic peptide (ANP) primarily controls blood volume in mammals (Ruskoaho 1992, Loretz \& Pollina 2000). ANP is secreted in response to an increase in blood volume and promotes excretion of water and $\mathrm{Na}^{+}$by the kidney, and functions to inhibit $\mathrm{Na}^{+}$appetite and thirst, thus preventing further accumulation of $\mathrm{Na}^{+}$and water. On the other hand, ANP likely responds to the plasma $\mathrm{Na}^{+}$level, rather than blood volume, in eel, a euryhaline fish, which means it can adapt to both freshwater and seawater (Takei \& Hirose 2002, Takei et al. 2006). During seawater adaptation, which tends to decrease blood volume but increase plasma $\mathrm{Na}^{+}$concentration, ANP is temporally secreted and prevents excess $\mathrm{Na}^{+}$absorption (Tsukada et al. 2005, Tsukada \& Takei 2006). In zebrafish, the anp gene has been isolated and the expression is confined to the atrium during embryogenesis; the regulatory function remains unclear (Berdougo et al. 2003).

The renin-angiotensin system (RAS) also plays a critical role in blood volume control in mammals, although the regulatory direction is opposite that of ANP (Robertson 1993, Zhu \& Herbert 1996). In response to a decrease in blood pressure, the system basically promotes dipsogenesis and reduces excretion of water and $\mathrm{Na}^{+}$by the kidney directly and indirectly. Renin, an enzyme that converts angiotensinogen to angiotensin I, is secreted from the juxtaglomerular cells of the kidney in response to a decrease in blood pressure (Gomez et al. 1988, Jones et al. 1990). In zebrafish, expression of renin has been shown in the juxtaglomerular cells, although no physiological function has been analyzed yet (Liang et al. 2004).

Prolactin and Growth Hormone $(\mathrm{GH})$ are protein hormones that share a common structure and are mainly 
expressed in the pituitary gland (Sakamoto \& McCormick 2006). In mammals, function of Prolactin is best known for promotion lactation in the mammary gland (Riddle et al. 1933, Bole-Feysot et al. 1998, Gerlo et al. 2006). GH controls the growth of organisms through expression of insulin-like growth factor I (Kaplan 1999, Kopchick 2001). In teleost fish, both Prolactin and $\mathrm{GH}$ are involved in osmoregulation (Sakamoto \& McCormick 2006). In a variety of freshwater and euryhaline teleosts, prolactin is required for adaptation to freshwater by promoting ion uptake and reducing water and ion permeability of the osmoregulatory surfaces, i.e. the gill, intestine, and kidney (Manzon 2002). On the other hand, GH has been viewed as seawater adapting in euryhaline species, as exogenous treatment of $\mathrm{GH}$ increased salinity tolerance (Smith 1956, Sakamoto et al. 1993). In zebrafish, both the prolactin and gh genes have been isolated and shown to be expressed in the pituitary gland during embryogenesis (Herzog et al. 2003, Liu et al. 2006).

Parathyroid hormone (PTH) is a regulator of $\mathrm{Ca}^{2+}$ homeostasis in mammals (Jüppner et al. 2000). A decrease in $\mathrm{Ca}^{2+}$ level in blood stimulates PTH secretion from the parathyroid glands. PTH accelerates bone resorption in osteoclasts and $\mathrm{Ca}^{2+}$ reabsorption in the kidney resulting in a recovery of $\mathrm{Ca}^{2+}$ levels in blood. It is not clear whether teleost fish have a similar PTH function, as they lack anatomically distinct parathyroid glands (Goodrich 1930, Hyman 1942, Copp 1969). However, PTH-related protein $(\mathrm{PTHrP})$, derived from a common ancestor gene and sharing a receptor (PTH1R) with $\mathrm{PTH}$, has been well studied in fish (Abbink \& Flik 2006, Guerreiro et al. 2007), and the hypercalcemic function of PTHrP has been shown in sea bream (Abbink et al. 2004, Fuentes et al. 2006). Although their function remains unclear, recent studies have identified PTH homologs in zebrafish and in pufferfish (Gensure et al. 2004, Okabe \& Graham 2004). The zebrafish pth genes, pth1, and pth 2 are predominantly expressed in the lateral line and in the ventral neural tube of the central nervous system (CNS; Hogan et al. 2005).

In this study, we examined the capability of the endocrine system in zebrafish larva to respond to an environmental salinity challenge. Zebrafish have been extensively utilized as a model vertebrate for studies on embryogenesis and organogenesis, and the strengths of this model organism in studies an genetic approaches and the manipulation of gene expression and genome information, is that it is be adaptable for investigation of physiological functions, e.g. ionic and osmotic homeostasis (McGonnell \& Fowkes 2006). Since zebrafish is a stenohaline freshwater fish that can adapt to salinity challenges in freshwater but not in seawater, we cultured the larvae in freshwater with different salinities and examined the endocrine response. Following investigation of the salinity range to which larvae can adapt, we investigated the transcriptional response of five endocrine genes: anp, renin, prolactin, gh, and $p t h 1$, to different salinities. We also analyzed the response of these genes to specific ions by altering the ionic composition of the medium.

\section{Materials and Methods}

\section{Zebrafish culture}

The wild-type zebrafish TL line was maintained as described earlier (Westerfield 1995). Fertilized eggs were incubated in $1 \times$ freshwater $(1 \times \mathrm{FW}: 60 \mathrm{mg}$ ocean salt (Rohtomarine, ReiSea, Tokyo, Japan) per 1 liter distilled water, $\mathrm{pH} 6 \cdot 7-7 \cdot 4$ ) at $28 \cdot 5{ }^{\circ} \mathrm{C}$ unless otherwise mentioned. Here, $1 \times \mathrm{FW}$ was used as our standard freshwater medium and corresponds to 'Fish Water' as described in 'The Zebrafish Book' (Westerfield 1995). The concentration of major ions in and osmolarity of $1 \times \mathrm{FW}$ are listed in Table 1 . The animal protocols and procedures were approved by the Institutional Animal Care and Use Committee of Tokyo Institute of Technology.

\section{Acclimation test of zebrafish larvae in freshwater with different salinities}

In addition to $1 \times \mathrm{FW}$, we prepared $1 / 20 \times \mathrm{FW}(3 \mathrm{mg}$ ocean salt per liter, $\mathrm{pH} 7 \cdot 2)$ as a dilute freshwater medium and $100 \times \mathrm{FW}(6 \mathrm{~g}$ ocean salt per liter, $\mathrm{pH} 6 \cdot 1-6 \cdot 8)$ as a

Table 1 The concentration of the major ions and osmolarity in conditioned freshwater

\begin{tabular}{|c|c|c|c|c|c|c|c|}
\hline & \multicolumn{6}{|c|}{ Ion/osmolyte $(\mu \mathrm{M})$} & \multirow[t]{2}{*}{$\begin{array}{l}\text { Osmolarity } \\
(\mathrm{mOsmol} / \mathrm{l})\end{array}$} \\
\hline & $\mathrm{Na}^{+}$ & $\mathrm{K}^{+}$ & $\mathrm{Ca}^{2+}$ & $\mathrm{Cl}^{-}$ & $\mathrm{SO}_{4}^{2-}$ & Sorbitol & \\
\hline $1 \times \mathrm{FW}$ & 686 & $14 \cdot 6$ & $16 \cdot 2$ & 804 & $41 \cdot 6$ & - & $1 \cdot 64$ \\
\hline $1 / 20 \times F W$ & $34 \cdot 3$ & $0 \cdot 730$ & $0 \cdot 810$ & $40 \cdot 2$ & $2 \cdot 08$ & - & $0 \cdot 0821$ \\
\hline $100 \times \mathrm{FW}$ & $68 \cdot 6 \times 10^{3}$ & $1.46 \times 10^{3}$ & $1.62 \times 10^{3}$ & $80 \cdot 4 \times 10^{3}$ & $4 \cdot 16 \times 10^{3}$ & - & 164 \\
\hline \multicolumn{8}{|c|}{$1 / 20 \times$ FW + supplement } \\
\hline + sorbitol & $34 \cdot 3$ & $0 \cdot 730$ & $0 \cdot 810$ & $40 \cdot 2$ & $2 \cdot 08$ & $1.56 \times 10^{3}$ & $1 \cdot 64$ \\
\hline$+\mathrm{NaCl}$ & 686 & $0 \cdot 730$ & $0 \cdot 810$ & 692 & $2 \cdot 08$ & - & $1 \cdot 39$ \\
\hline$+\mathrm{KCl}$ & $34 \cdot 3$ & $14 \cdot 6$ & $0 \cdot 810$ & $54 \cdot 1$ & $2 \cdot 08$ & - & $0 \cdot 110$ \\
\hline$+\mathrm{NaCl}, \mathrm{KCl}$ & 686 & $14 \cdot 6$ & $0 \cdot 810$ & 706 & $2 \cdot 08$ & - & $1 \cdot 41$ \\
\hline$+\mathrm{CaCl}_{2}$ & $34 \cdot 3$ & $0 \cdot 730$ & $16 \cdot 2$ & $71 \cdot 0$ & $2 \cdot 08$ & - & $0 \cdot 128$ \\
\hline$+\mathrm{NaCl}, \mathrm{KCl}, \mathrm{CaCl}_{2}$ & 686 & $14 \cdot 6$ & $16 \cdot 2$ & 737 & $2 \cdot 08$ & - & $1 \cdot 44$ \\
\hline
\end{tabular}


concentrated medium (Table 1). For long-term acclimation to $1 / 20 \times \mathrm{FW}$ and $100 \times \mathrm{FW}, 10-25$ fertilized embryos reared in $1 \times \mathrm{FW}$ were dechorionated at 24 hours postfertilization $(\mathrm{hpf})$, rinsed with $1 / 20 \times \mathrm{FW}$ or $100 \times \mathrm{FW}$, and cultured in $50 \mathrm{ml} 1 / 20 \times \mathrm{FW}$ or $100 \times \mathrm{FW}$ in $100 \mathrm{~mm}$ Petri dish for 6 days respectively (Fig. 1A). For short-term exposure to $1 / 20 \times \mathrm{FW}$ and $100 \times \mathrm{FW}, 10-25$ fertilized embryos reared in $1 \times \mathrm{FW}$ were dechorionated at $24 \mathrm{hpf}$, rinsed with $1 \times \mathrm{FW}$ and continuously cultured in $50 \mathrm{ml} 1 \times \mathrm{FW}$ in $100 \mathrm{~mm}$ petri dish. At 6 days postfertilization $(\mathrm{dpf})$, the larvae were rinsed with $1 / 20 \times \mathrm{FW}$ or $100 \times \mathrm{FW}$ and cultured in $50 \mathrm{ml} 1 / 20 \times \mathrm{FW}$ or $100 \times$ FW in a $100 \mathrm{~mm}$ petri dish for $24 \mathrm{~h}$ respectively (Fig. 1A). To test the ability of recovery from exposure to dilute or concentrated freshwater, 24-hpf embryos were cultured in
$1 / 20 \times \mathrm{FW}$ or $100 \times \mathrm{FW}$ as described above, and were transferred back to $1 \times \mathrm{FW}$ on $6 \mathrm{dpf}(=5$ days postacclimation) and cultured for $24 \mathrm{~h}$. In a series of acclimation tests in $1 / 20 \times \mathrm{FW}$ with particular supplements (Table 1), the dechorionated embryos were cultured in the conditioned water for 6 days as described for longterm acclimation to $1 / 20 \times \mathrm{FW}$. As a control, dechorionated embryos were continuously cultured in $1 \times \mathrm{FW}$ until $7 \mathrm{dpf}$. During the incubation, dead larvae were removed every day. On $7 \mathrm{dpf}$, living larvae were counted and the morphology was recorded and photographed with MZ16F stereomicroscope (Leica, Germany). We note that the zebrafish larvae were not fed during these tests, and we have verified that the larvae are able to survive without feeding at least until $10 \mathrm{dpf}$.

A

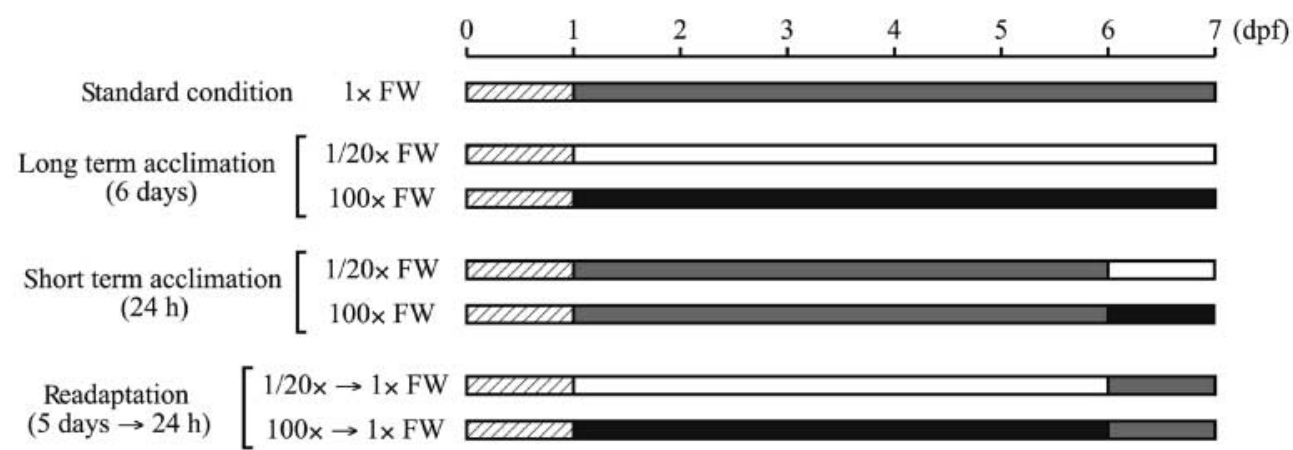

WU: in $1 \times \mathrm{FW}$ (in chorion),

: in $1 \times \mathrm{FW}, \square$ : in $1 / 20 \times \mathrm{FW}$, : in $100 \times \mathrm{FW}$

B

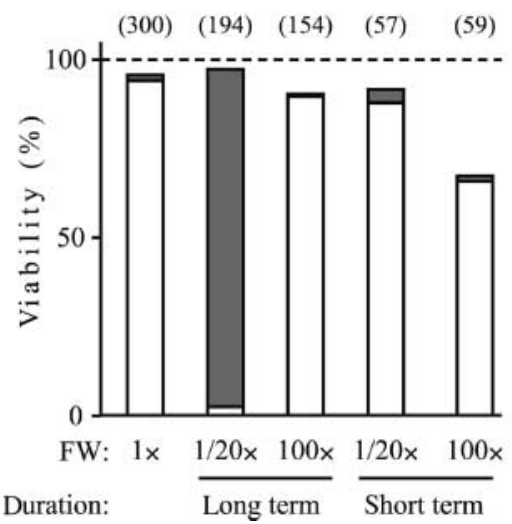

C

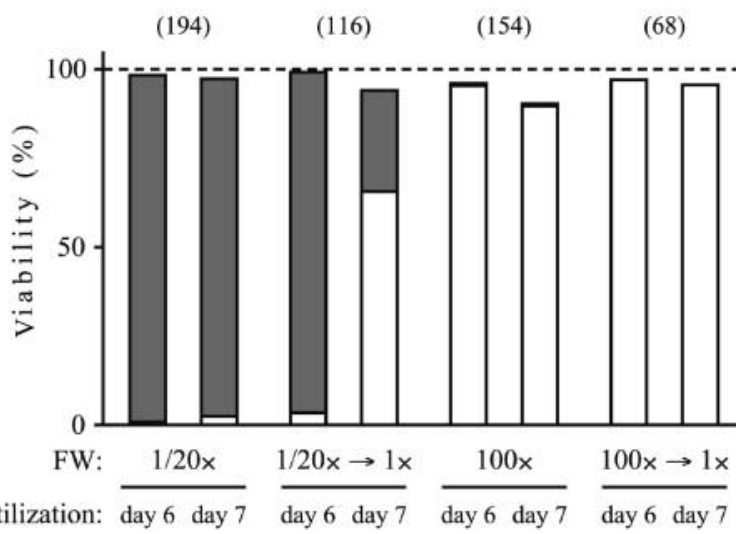

Figure 1 Larval development of zebrafish cultured in different salinity conditions. (A) Schematic representation of acclimation protocols. $1 \times$ FW (shaded box): standard freshwater medium, 1/20× FW (open box): 20-fold diluted freshwater medium, 100 $\times$ FW (solid box): 100 -fold concentrated freshwater medium (see Materials and Methods, and Table 1). The length of culture in each medium is represented in days post-fertilization (dpf) across the top of the schematic. We note that prior to the acclimation test, zebrafish embryos developed for $24 \mathrm{~h}$ in the chorion in $1 \times \mathrm{FW}$ medium (hatched box). (B) Viability of zebrafish larvae cultured in $1 / 20 \times \mathrm{FW}$ or $100 \times$ FW under long- (24 hpf to $7 \mathrm{dpf}$ ) or short-term (6 to $7 \mathrm{dpf}$ ) acclimation protocols. (C) Viability of zebrafish larvae post-long-term acclimation in $1 / 20 \times \mathrm{FW}$ or $100 \times \mathrm{FW}$, and after readaptation. Open and shaded boxes indicate the percentage of living larvae developing normally and those lacking swimbladder respectively. Numbers in parentheses represent the number of larvae examined in each condition. 


\section{Quantitative PCR}

At the end of the acclimation tests, for each condition, larvae $(n=10-25)$ in a dish were collected and total RNA was extracted with the RNeasy Lipid Tissue Kit (Qiagen) followed by the RNeasy MiniElute Cleanup Kit (Qiagen) according to the manufacturer's instruction. The RNA was dissolved in $14 \mu \mathrm{l}$ diethyl pyrocarbonate-treated water, and its concentration was measured spectrophotometrically at $260 \mathrm{~nm}$. Single-stranded cDNA was prepared from $500 \mathrm{ng}$ total RNA with oligo $(\mathrm{dT})$ primer in a $20 \mu \mathrm{l}$ reaction volume using Superscript III First-Strand System (Invitrogen) and finally diluted in $40 \mu \mathrm{l}$ diethyl pyrocarbonate-treated water. Realtime PCR was set up using $2 \cdot 5 \mu \mathrm{l}$ cDNA, $12 \cdot 5 \mu 12 \times \mathrm{SYBR}$ Green Master Mix (Applied Biosystems, ABI, Foster City, CA, USA), and $50 \mathrm{nM}$ each of forward and reverse primers in a total volume of $25 \mu \mathrm{l}$. The real-time PCR was run for 45 cycles on the 7500 Real-Time PCR System (ABI) according to the manufacturer's protocol. Primers for each target gene were designed to generate a product around $55 \mathrm{bp}$ in size, and their efficiency was validated by graphical representation of slope and fluorescence intensity/cycle number (see Table 2 for primer sequence). The amount of cDNA in a sample was calculated by comparing the threshold cycle $\left(C_{t}\right)$ in the sample against a standard curve generated from a series of diluted cDNAs that were prepared from RNA obtained from larvae raised in standard freshwater $(1 \times \mathrm{FW})$ with primers for each target. The amount of ribosomal protein L9 (rpl9) in each sample was used for normalization. The resultant value in each condition was obtained from at least three independent acclimation experiments and calibrated to that in $1 \times \mathrm{FW}$ and represented on a logarithmic scale. We also used the gapdh gene (GenBank accession number AY818346) as a normalization control for quantitative PCR and obtained results consistent with the rpl9 control (data not shown).

\section{Whole mount in situ hybridization}

Whole mount in situ hybridization was performed as previously described with brief modifications (Novak \& Ribera 2003, Esaki et al. 2007), using a digoxigenin-labeled RNA probe for anp corresponding to a 365-bp fragment of the cDNA (Genbank accession number NM_198800; nucleotide (nt) 104-468), renin corresponding to a 591-bp fragment of the cDNA (NM_212860; nt 537-1127), prolactin corresponding to a 550-bp fragment of the cDNA (NM_181437; nt 214-763), gh corresponding to a 451-bp fragment of the cDNA (NM_001020492; nt 213-663), pth1 corresponding to a 571-bp fragment of the cDNA (NM_212950; nt 54-624), or podocin corresponding to a 637-bp fragment of the cDNA (AY956356; nt 706-1342). A fluorescein-labeled RNA probe was also prepared for renin using a cDNA fragment identical to the digoxigenin-labeled probe. In situ hybridization with single digoxigenin-labeled probe was carried out using the wild-type TL strain. After staining with NBT/BCIP color development substrate (Promega), larvae were depigmented and permeablized extensively by incubation with $20 \% \quad \mathrm{H}_{2} \mathrm{O}_{2}$ in PBT (137 mM NaCl, $27 \mathrm{mM} \mathrm{KCl,} 10 \mathrm{mM} \mathrm{Na} \mathrm{HPO}_{4}, 2 \mathrm{mM}$ $\mathrm{KH}_{2} \mathrm{PO}_{4}, 0 \cdot 1 \%$ Tween-20, pH 7-4) overnight or longer. For double in situ hybridization, 7-dpf albino larvae were hybridized simultaneously with a digoxigenin-labeled podocin probe and a fluorescein-labeled renin probe. Following incubation with anti-digoxigenin Fab fragment conjugated with alkaline phosphatase (diluted 1:4000, Roche), podocin signal was first developed in red using SIGMAFAST Fast Red TR/Napthol AS-MX (Sigma). Subsequently, larvae were incubated with anti-fluorescein Fab fragment conjugated with alkaline phosphatase (diluted 1:2000, Roche) and renin signal was developed in purple with NBT/BCIP color development substrate.

\section{Results}

Larval development of zebrafish in freshwater with different salinities

Prior to examining the endocrine response in zebrafish larvae to environmental salinity, we examined the range of salinities in which the larvae were able to survive. In this study, standard freshwater $(1 \times \mathrm{FW})$ was the medium used for the routine culture of zebrafish embryos/larvae. We also prepared $1 / 20 \times$ FW and $100 \times \mathrm{FW}$, and transferred the larvae to these media at different developmental points (Fig. 1A). When larvae were transferred from $1 \times \mathrm{FW}$ to $1 / 20 \times \mathrm{FW}$ at $24 \mathrm{hpf}$ and

Table 2 Primers used for quantitative PCR

\begin{tabular}{|c|c|c|c|c|c|}
\hline & $\begin{array}{l}\text { GenBank } \\
\text { accession no. }\end{array}$ & $\begin{array}{l}\text { Forward } \\
\text { primer }\end{array}$ & $\begin{array}{l}\text { Reverse } \\
\text { primer }\end{array}$ & $\begin{array}{l}\text { Product } \\
\text { size }(b p)\end{array}$ & $\begin{array}{l}\text { Amplification } \\
\text { efficiency }(\%)\end{array}$ \\
\hline \multicolumn{6}{|l|}{$\begin{array}{l}\text { Target } \\
\text { gene }\end{array}$} \\
\hline anp & NM_198800 & AGCAACATGGCCAAGCTCAAG & CAGGGCСТССТСАAАCTGC & 51 & $89 \cdot 4$ \\
\hline renin & NM_212860 & TGAACTGGCAGAAGGAGGGTATA & GCAACAGTGGGCAACAACCT & 63 & $85 \cdot 4$ \\
\hline prolactin & NM_181437 & GGCCTGGAGCACGTCGTA & ACGGGAGAGTGGACAGGTTGT & 61 & $98 \cdot 8$ \\
\hline gh & NM_001020492 & CACTGAGAAACTGGTGGACCTG & TCССTTGATGAGCACGCTG & 52 & $86 \cdot 5$ \\
\hline
\end{tabular}


cultured for 6 days, viability was similar to that of control larvae ( $>95 \%$ viability), which were continuously cultured in $1 \times$ FW for 7 days (Fig. 1B). However, we observed that most of the larvae cultured in $1 / 20 \times \mathrm{FW}$ did not develop the swimbladder, which usually appears by $5 \mathrm{dpf}$ (Figs $1 \mathrm{~B}$ and $2 \mathrm{~A}$ and $\mathrm{B})$. Otherwise, larval morphology appeared normal. These results suggest that $1 / 20 \times \mathrm{FW}$ is likely to be close to the lower limit of ionic concentration in which zebrafish larvae can survive, although development is affected. Conversely, when zebrafish larvae were transferred from $1 \times \mathrm{FW}$ to $100 \times \mathrm{FW}$ at $24 \mathrm{hpf}$ and cultured for 6 days, the larvae survived as well as controls without any detectable defects in morphology (Figs $1 \mathrm{~B}$ and 2C).

Next, we examined the effects of short-term acclimation to $1 / 20 \times \mathrm{FW}$ and $100 \times \mathrm{FW}$ (Fig. 1A). The zebrafish larvae that were transferred from $1 \times \mathrm{FW}$ to $1 / 20 \times \mathrm{FW}$ at $6 \mathrm{dpf}$ and cultured for $24 \mathrm{~h}$ exhibited high viability with well-developed swimbladders (Fig. 1B). Interestingly, when the larvae were transferred to $100 \times \mathrm{FW}$ at $6 \mathrm{dpf}$ and cultured for $24 \mathrm{~h}$, viability was reduced to approximately two-thirds, although the survivors did not show any obvious defects in morphology (Fig. 1B). These results suggest that in $100 \times$ FW 6-dpf-larvae cannot quickly adapt the saline challenge, but require a longer acclimation time, beginning at a younger stage.

We also analyzed effects of readaptation to the standard freshwater condition from the dilute and concentrated media (Fig. 1A). Following culture in $1 / 20 \times$ FW for 5 days ( 24 hpf to $6 \mathrm{dpf})$, zebrafish larvae were transferred back to $1 \times \mathrm{FW}$ and cultured for $24 \mathrm{~h}$. Readaptation did not affect viability but did result in the development of the swimbladder in a significant number of larvae (Figs 1C and 2D). This recovery was solely dependent on readaptation, as most of the larvae cultured in $1 /$ $20 \times$ FW continuously for 6 days ( $24 \mathrm{hpf}$ to $7 \mathrm{dpf}$ ) did not develop the swimbladder (Fig. 1C). These results suggest that the morphological defect caused by culture in $1 / 20 \times \mathrm{FW}$ is reversible and quickly recovered under standard salinity
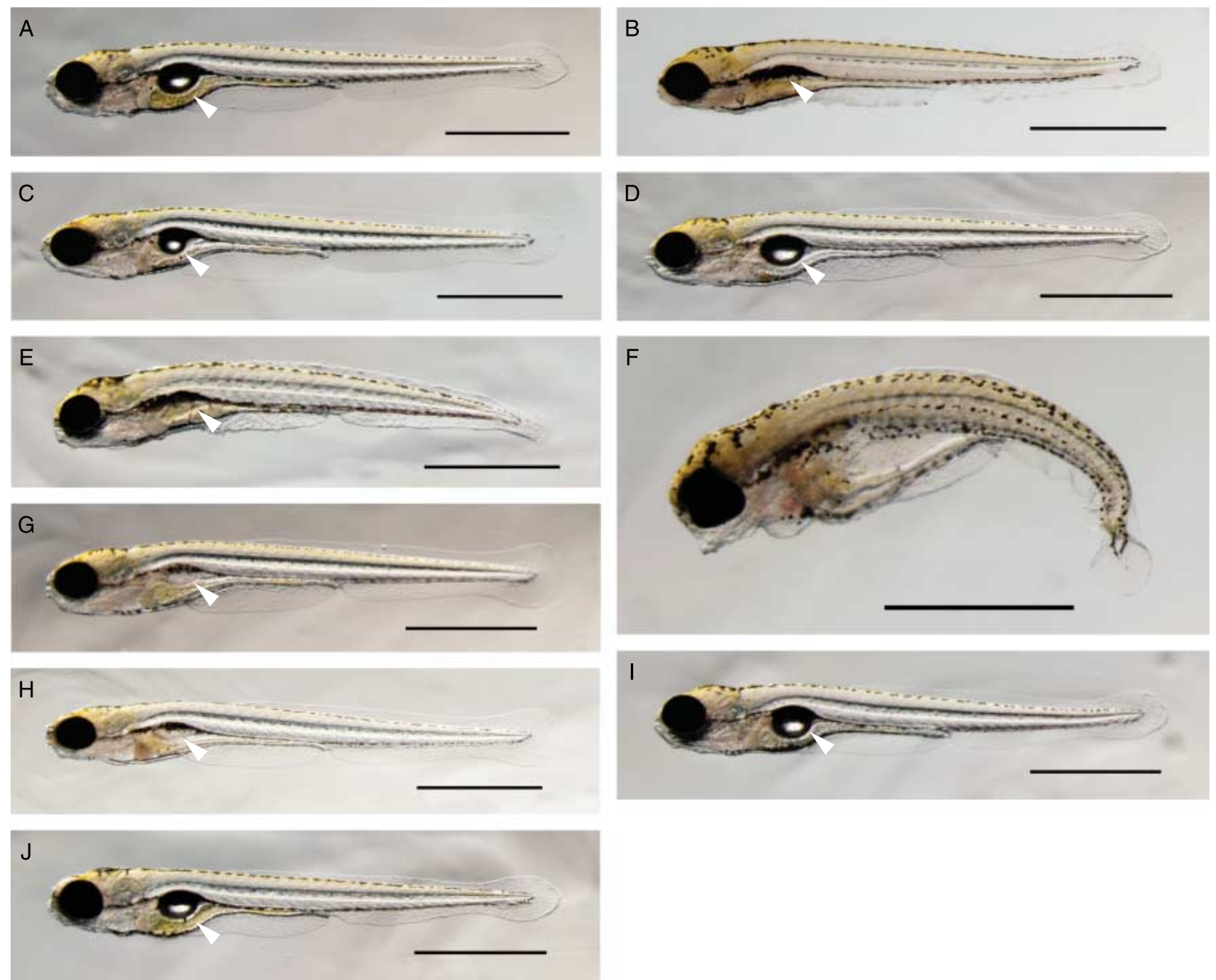

Figure 2 Morphology of zebrafish larvae cultured in different salinity conditions. (A-D) Morphology of 7 dpf zebrafish larvae cultured in $1 \times$ FW (A), acclimated in 1/20× FW (long term) (B), acclimated in $100 \times \mathrm{FW}$ (long term) (C), and acclimated in $1 / 20 \times$ FW for 5 days and then in $1 \times \mathrm{FW}$ for $24 \mathrm{~h}$ (readaptation) (D). (E-J) Morphology of 7-dpf zebrafish larvae cultured in $1 / 20 \times \mathrm{FW}+$ sorbitol $(\mathrm{E})$, in $1 / 20 \times \mathrm{FW}+\mathrm{NaCl}(\mathrm{F})$, in $1 / 20 \times \mathrm{FW}+\mathrm{KCl}(\mathrm{G})$, in $1 / 20 \times \mathrm{FW}+\mathrm{NaCl}, \mathrm{KCl}(\mathrm{H})$, in $1 / 20 \times \mathrm{FW}+\mathrm{CaCl}_{2}(\mathrm{I})$, and in $1 / 20 \times \mathrm{FW}+\mathrm{NaCl}, \mathrm{KCl}, \mathrm{CaCl} 2(\mathrm{~J})$. Arrowheads indicate the swimbladder (missing in $\mathrm{B}, \mathrm{E}, \mathrm{G}$, and $\mathrm{H}$ ). Scale bars, $1 \mathrm{~mm}$. 
Table $3 \mathrm{PO}_{2} / \mathrm{PCO}_{2}$ in conditioned freshwater. Mean and S.E.M. values were obtained by triplicate measurements

\section{In stock}

\section{Medium}

$1 \times \mathrm{FW}$

$1 / 20 \times \mathrm{FW}$

$100 \times \mathrm{FW}$
$25 \cdot 31 \pm 0 \cdot 13$
$25 \cdot 35 \pm 0 \cdot 44$
$25 \cdot 91 \pm 0 \cdot 56$
In cultured dish

$27 \cdot 28 \pm 2 \cdot 25$

$24 \cdot 49 \pm 0 \cdot 20$

$23 \cdot 55 \pm 0 \cdot 21$
${ }^{\mathrm{a}} \mathrm{PO}_{2}(\mathrm{mmHg})$ and $\mathrm{PCO}_{2}(\mathrm{mmHg})$ in stock solution of each medium (at $28.5^{\circ} \mathrm{C}$ ). were measured by Radiometer ABL505 (Radiometer, Copenhagen Denmark) and $\mathrm{PO}_{2} / \mathrm{PCO}_{2}$ was calculated.

${ }^{\mathrm{b}} \mathrm{PO} 2(\mathrm{mmHg})$ and PCO2 $(\mathrm{mmHg})$ in Petri dishes in which zebrafish larvae $(n=20)$ were cultured in each medium for 6 days ( $24 \mathrm{hpf}$ to $7 \mathrm{dpf})$ were measured by Radiometer ABL505 (Radiometer) and $\mathrm{PO}_{2} / \mathrm{PCO}_{2}$ was calculated.

conditions. This finding also supports the notion that $1 / 20 \times$ FW is close to the lower limit of salinity in which zebrafish larvae can survive. Readaptation from $100 \times \mathrm{FW}$ to $1 \times \mathrm{FW}$ did not show any obvious effects on viability or morphology. Inflation of the swimbladder possibly depends on ratio of $\mathrm{PO}_{2}$ to $\mathrm{PCO}_{2}\left(\mathrm{PO}_{2} / \mathrm{PCO}_{2}\right)$ in different media (Randall et al. 2002). However, $\mathrm{PO}_{2} / \mathrm{PCO}_{2}$ did not show salinity-dependency among our conditioned media (Table 3).

\section{Endocrine response to environmental salinity}

Using $1 / 20 \times \mathrm{FW}$ and $100 \times \mathrm{FW}$ as our dilute and concentrated media respectively, we analyzed the expression level of endocrine genes in zebrafish larvae cultured under different salinity conditions. From a preliminary screen of more than 20 endocrine genes, including hormones, activating enzymes or receptors, we found that anp, renin, prolactin, gh, and pth1 appeared to respond to the environmental salinity challenge (data not shown). We further analyzed the response of these five endocrine genes. We first confirmed the previously reported expression of these genes at $7 \mathrm{dpf}$ (Fig. 3; Berdougo et al. 2003, Herzog et al. 2003, Liang et al. 2004, Hogan et al. 2005). When zebrafish larvae were cultured in $1 / 20 \times \mathrm{FW}$ for 6 days $(24 \mathrm{hpf}$ to $7 \mathrm{dpf}$ ), the expression level of anp and renin increased several fold when compared with the expression in larvae cultured in standard freshwater (Fig. 4). Remarkably, the expression of prolactin and $g h$ was elevated to nearly 100 -fold or more in $1 / 20 \times$ FW. pth1 expression also increased similarly to anp and renin. On the other hand, in larvae cultured in $100 \times$ FW for 6 days, the expression of anp, renin, prolactin, and pth 1 was significantly reduced, while $g h$ remained constant. Thus, the endocrine genes in zebrafish larvae respond at the transcriptional level to environmental salinity challenges.

When zebrafish larvae were acclimated in $1 / 20 \times \mathrm{FW}$ for $24 \mathrm{~h}$ (6-7 dpf), upregulation of prolactin and $g h$ was observed, although the elevation of each did not reach the levels observed after long-term acclimation (Fig. 4). Changes in anp, renin, and pth1 expression were not significant after shortterm acclimation. In contrast, after acclimation in $100 \times \mathrm{FW}$ for $24 \mathrm{~h}$, we observed reduced expression of anp, renin, prolactin, and pth1, but not $g h$.
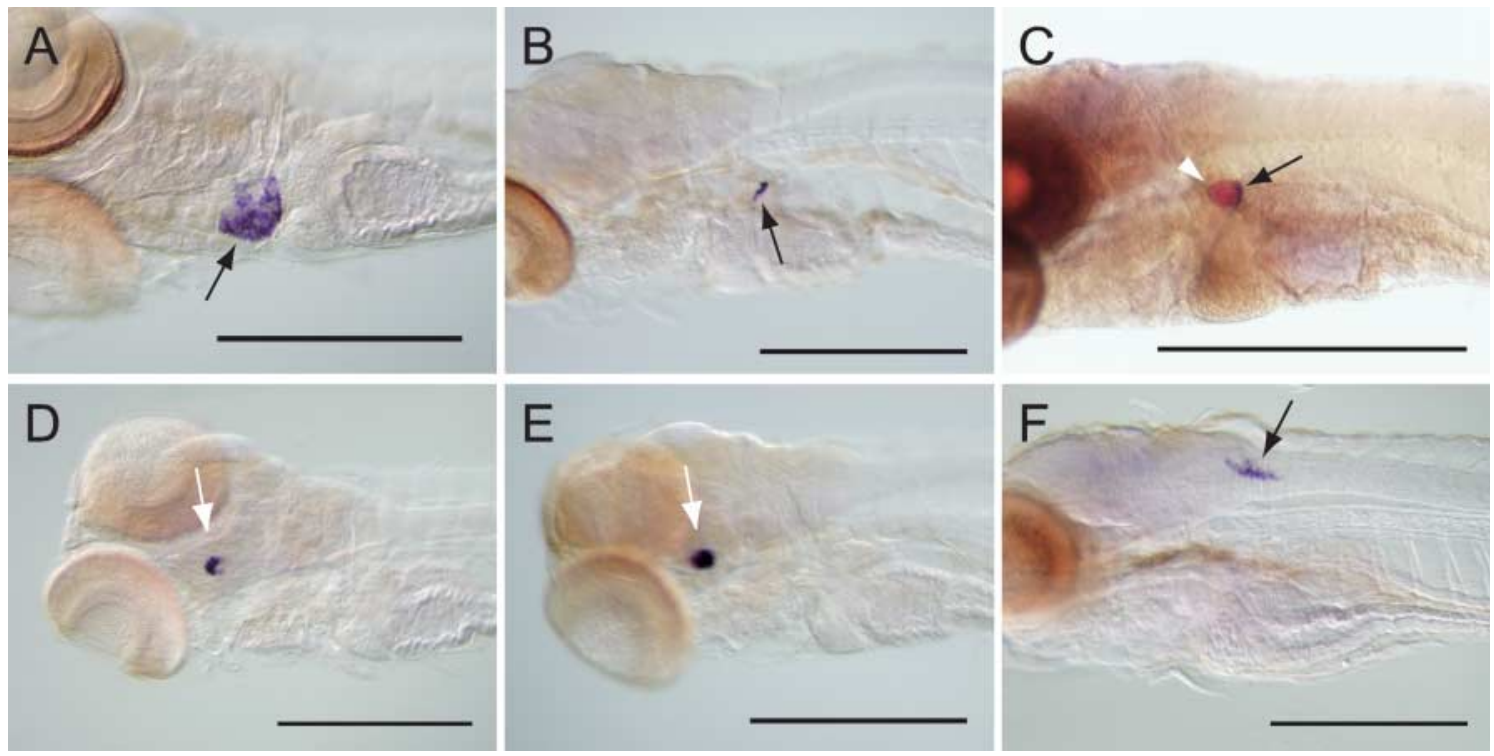

Figure 3 Expression of anp, renin, prolactin, gh, and pth1 in 7 dpf larvae. (A-F) Tissue-specific distribution of anp (A, ventral view), renin (B and C, lateral view), prolactin (D, dorsal view), gh (E, dorsal view), and pth1 ( $\mathrm{F}$, lateral view) was analyzed in zebrafish larvae at 7 dpf by whole mount in situ hybridization. Arrows indicate anp expression in the atrium (A), renin expression in the juxtaglomerular cells (B and C), prolactin and gh expression in the pituitary gland (C and D respectively), and pth1 expression in a portion of the ventral neural tube of the CNS (E). In panel (C), renin was co-stained with a glomerulus marker, podocin (GenBank accession number, NM_001018145). Podocin (red, arrowhead) and renin (purple, arrow) were expressed adjacent to each other, indicating that renin expression was in the juxtaglomerular cells. We note that except in (C) larvae are wild-type TL strain that have been depigmented by $20 \% \mathrm{H}_{2} \mathrm{O}_{2}$ after staining. In panel (C), we used an albino strain as the depigmentation process could cause the red staining to fade. Scale bars, $0.5 \mathrm{~mm}$. 


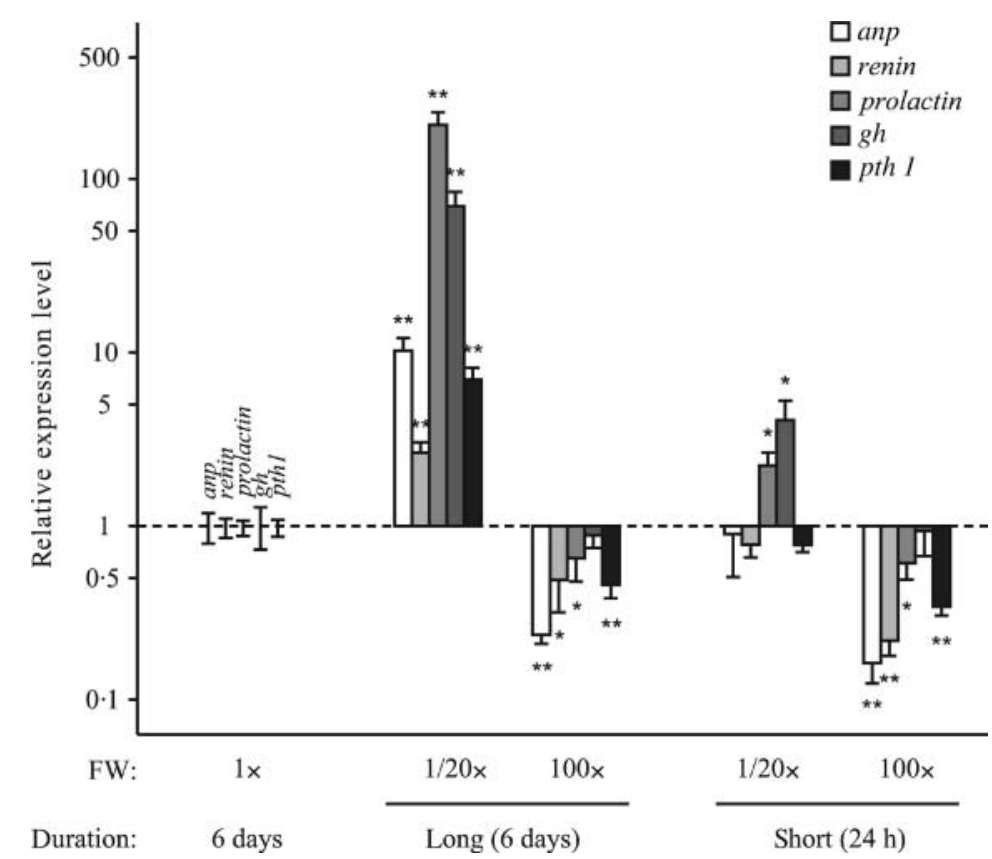

Figure 4 The expression level of endocrine genes depends on environmental salinities. Expression level of anp, renin, prolactin, gh, and pth 1 was measured in zebrafish larvae after long- and short-term acclimation to $1 / 20 \times$ FW or $100 \times$ FW. The expression level of each gene was normalized by comparison with the expression of RPL9. The mean value \pm S.E.M. in each condition was obtained from replicate acclimation experiments $(n=3-14)$ and were calibrated to expression in $1 \times \mathrm{FW}$ and represented on a logarithmic scale. S.E.M. value of each gene in $1 \times \mathrm{FW}$ was also normalized and plotted as an error bar. Asterisks indicate a significant difference from the expression level in $1 \times \mathrm{FW}$ as evaluated by a Mann-Whitney $U$-test $(* * P<0 \cdot 01, * P<0 \cdot 05)$.

Finally, we also analyzed expression level of these genes after readaptation to $1 \times \mathrm{FW}$ from $1 / 20 \times \mathrm{FW}$ and $100 \times$ FW. Following readaptation to $1 \times \mathrm{FW}$ for $24 \mathrm{~h}$ after 5 days culture in $1 / 20 \times \mathrm{FW}$, the expression of anp, renin, and pth1 was reduced to levels seen in standard conditions (Fig. 5). The expression level of prolactin and $g h$ after readaptation from $1 / 20 \times \mathrm{FW}$ appeared higher than the standard level but was not statistically significant. We also observed that the expression level of these genes returned to standard levels when larvae were readapted to $1 \times \mathrm{FW}$ for $24 \mathrm{~h}$ after 5 days culture in $100 \times \mathrm{FW}$ (Fig. 5).

\section{Effects on larval development of freshwater with aberrant ionic compositions}

Next, we addressed whether the endocrine genes analyzed above exhibit any osmolarity- and ion-specific responses by preparing freshwater in which the osmolarity and ionic compositions were modified with an organic obsolete or specific ion (Table 1). First, we examined the effects of reconstituted freshwater on viability and morphogenesis of zebrafish larvae. When we cultured larvae for 6 days ( $24 \mathrm{hpf}$ to $7 \mathrm{dpf}$ ) in $1 / 20 \times \mathrm{FW}$ with sorbitol, in, which the osmolarity was equal to $1 \times \mathrm{FW}$ but the ionic strength remained $1 / 20 \times$, viability was not affected (Fig. 6). However, most larvae did not develop a swimbladder, indicating that restoration of osmolarity is not sufficient for proper development of the swimbladder (Figs 2E and 6). Interestingly, in 1/20X FW with $\mathrm{NaCl}$, in which $\mathrm{Na}^{+}$was added so as to be equal to $1 \times$ $\left(\mathrm{Cl}^{-}\right.$and osmolarity was also recovered to $\left.0 \cdot 85 \times\right)$, while other ions remained at $1 / 20 \times$ concentration, the larvae exhibited severe morphological defects accompanied by a reduction of viability. When cultured in $1 / 20 \times \mathrm{FW}$ with $\mathrm{NaCl}$ for 6 days, not only was the viability reduced to $63 \%$ but also all of the survivors had a curled body and exhibited severe edema of the chest and abdomen (Figs $2 \mathrm{~F}$ and 6). These results indicate that normal $\mathrm{Na}^{+}$concentration becomes toxic for zebrafish larvae if it is unbalanced with respect to other ions. On the other hand, supplementation of $\mathrm{K}^{+}$did not show such toxicity: among larvae cultured in $1 / 20 \times \mathrm{FW}$ with $\mathrm{KCl}$, the viability was high and $\sim 50 \%$ of the larvae developed normally including the swimbladder (Figs $2 \mathrm{G}$ and 6). Furthermore, addition of $\mathrm{KCl}$ to $1 / 20 \times \mathrm{FW}$ with $\mathrm{NaCl}$ neutralized the toxicity caused by elevated $\mathrm{Na}^{+}$. When larvae were cultured for 6 days in $1 / 20 \times$ FW with $\mathrm{NaCl}$ and $\mathrm{KCl}$, in which both $\mathrm{Na}^{+}$and $\mathrm{K}^{+}$were raised to $1 \times$ concentration, viability, and morphology were recovered, although substantial numbers of the larvae still lacked the swimbladder (Figs $2 \mathrm{H}$ and 6). In contrast to supplementation with $\mathrm{Na}^{+}$and $\mathrm{K}^{+}$, supplementation of $\mathrm{Ca}^{2+}$ promoted normal development. In $1 / 20 \times \mathrm{FW}$ with $\mathrm{CaCl}_{2}$, in which $\mathrm{Ca}^{2+}$ was equal to $1 \times$ but other ions remained $1 / 20 \times$ concentration 


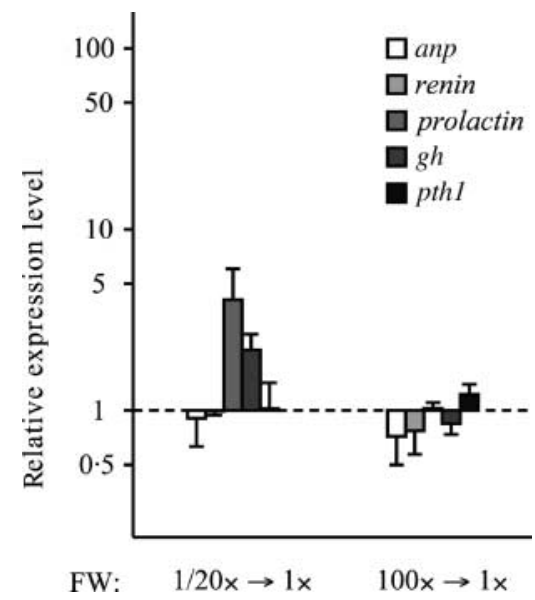

Figure 5 Expression level of endocrine genes after readaptation to standard freshwater medium, following culture in dilute or concentrated media. Expression level of anp, renin, prolactin, gh, and pth 1 was measured in zebrafish larvae cultured in $1 / 20 \times \mathrm{FW}$ or $100 \times \mathrm{FW}$ for 5 days and then in $1 \times \mathrm{FW}$ for $24 \mathrm{~h}$. The expression level of each gene obtained from replicate experiments $(n \geq 3)$ was normalized, calibrated and represented as described in Fig. 4. We note that evaluation by Mann-Whitney $U$-test did not show any significant differences in expression levels for any gene between $1 \times \mathrm{FW}$ and readaptation conditions.

$\left(\mathrm{Cl}^{-}\right.$was $\left.\sim 1 / 10 \times\right)$, larvae developed normally with high viability (Figs $2 \mathrm{I}$ and 6). In $1 / 20 \times \mathrm{FW}$ with $\mathrm{NaCl}, \mathrm{KCl}$, and $\mathrm{CaCl}_{2}$, the larvae also developed normally (Figs $2 \mathrm{~J}$ and 6 ). These results suggest that it is likely the limited $\mathrm{Ca}^{2+}$ in $1 / 20 \times \mathrm{FW}$ that causes the abnormal development of zebrafish larvae.

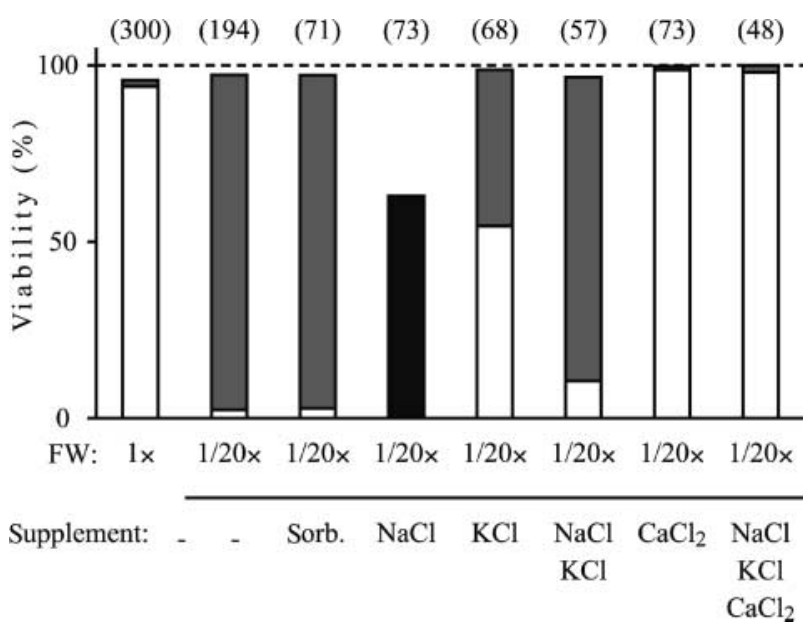

Figure 6 Viability of zebrafish larvae in dilute freshwater with supplementation of an organic osmolyte or specific ions. Viability of 7 -dpf zebrafish larvae was analyzed after culturing for 6 days (24 hpf to $7 \mathrm{dpf}$ ) in $1 / 20 \times \mathrm{FW}$ with a variety of supplements (see Materials and Methods, and Table 1). Open and shaded boxes indicate the percentage of living larvae developing normally and those lacking swimbladder respectively. Solid box indicates the percentage of larvae developing abnormally with severe edema. Numbers in parentheses represents the number of larvae examined in each condition.
Endocrine response to ambient salinity with aberrant ionic composition

We analyzed the expression level of anp, renin, prolactin, gh, and pth1 in the modified freshwater media. In larvae cultured in $1 / 20 \times \mathrm{FW}$ with sorbitol for 6 days ( $24 \mathrm{hpf}$ to $7 \mathrm{dpf}$ ), expression level of these genes was very similar to expression in $1 / 20 \times \mathrm{FW}$ (Fig. 7). This is consistent with our observation that supplementation of $1 / 20 \times \mathrm{FW}$ with sorbitol did not alter viability or morphology. In $1 / 20 \times$ FW with $\mathrm{NaCl}$, all genes except renin were further upregulated when compared with expression in larvae cultured in $1 / 20 \times \mathrm{FW}$. In $1 / 20 \times \mathrm{FW}$ with $\mathrm{KCl}$, expression of renin, prolactin, $g h$, and $p t h 1$ was significantly downregulated from levels seen in $1 / 20 \times \mathrm{FW}$. In $1 / 20 \times \mathrm{FW}$ with $\mathrm{NaCl}$ and $\mathrm{KCl}$, the expression level of these genes was similar to expression in $1 / 20 \times \mathrm{FW}$. Only pth 1 expression was significantly reduced from levels seen in $1 / 20 \times \mathrm{FW}$. The upregulation of prolactin, $g h$, and pth 1 by supplementation with $\mathrm{NaCl}$ is somehow neutralized by the addition of $\mathrm{K}^{+}$. In $1 / 20 \times \mathrm{FW}$ with $\mathrm{CaCl}_{2}$, consistent with the promotion of normal development, expression of all the endocrine genes except anp was significantly reduced when compared with expression in $1 / 20 \times \mathrm{FW}$. We observed that expression of these genes was further downregulated in $1 / 20 \times \mathrm{FW}$ with $\mathrm{NaCl}, \mathrm{KCl}$ and $\mathrm{CaCl}_{2}$. Thus, the endocrine genes in zebrafish larvae are able to respond to environmental salinity, and each gene has a different response to individual ions.

\section{Discussion}

In this report, we examine the response of the zebrafish endocrine system to environmental salinity challenges. In teleost fish including zebrafish, ionic and osmotic homeostasis of the body fluid is directly affected by environmental salinity because the plasma contacts the environment through respiratory epithelia. Therefore, as a homeostatic strategy, the endocrine system in teleost fish must respond to the environmental salinity. Furthermore, by manipulating the environmental salinity, we can perturb the ionic and osmotic balance of the body fluid in teleost fish and examine the endocrine response, as a model for studying homeostasis. Using freshwater with altered salinities, we have detected a transcriptional response of several endocrine genes in zebrafish larvae to the external salinity. Interestingly, anp and renin were regulated in the same direction: they were upregulated in the dilute condition $(1 / 20 \times \mathrm{FW})$ and downregulated after culture in the concentrated medium $(100 \times \mathrm{FW}$; Fig. 4). This response is quite different from that observed in mammals where ANP and Renin/RAS have opposite effects on blood volume control: ANP responds to hypervolemia and promotes excretion of water and $\mathrm{Na}^{+}$, while Renin responds to hypovolemia and RAS promotes reabsorption of water and $\mathrm{Na}^{+}$(Ruskoaho 1992, Robertson 1993). These differences between teleosts 


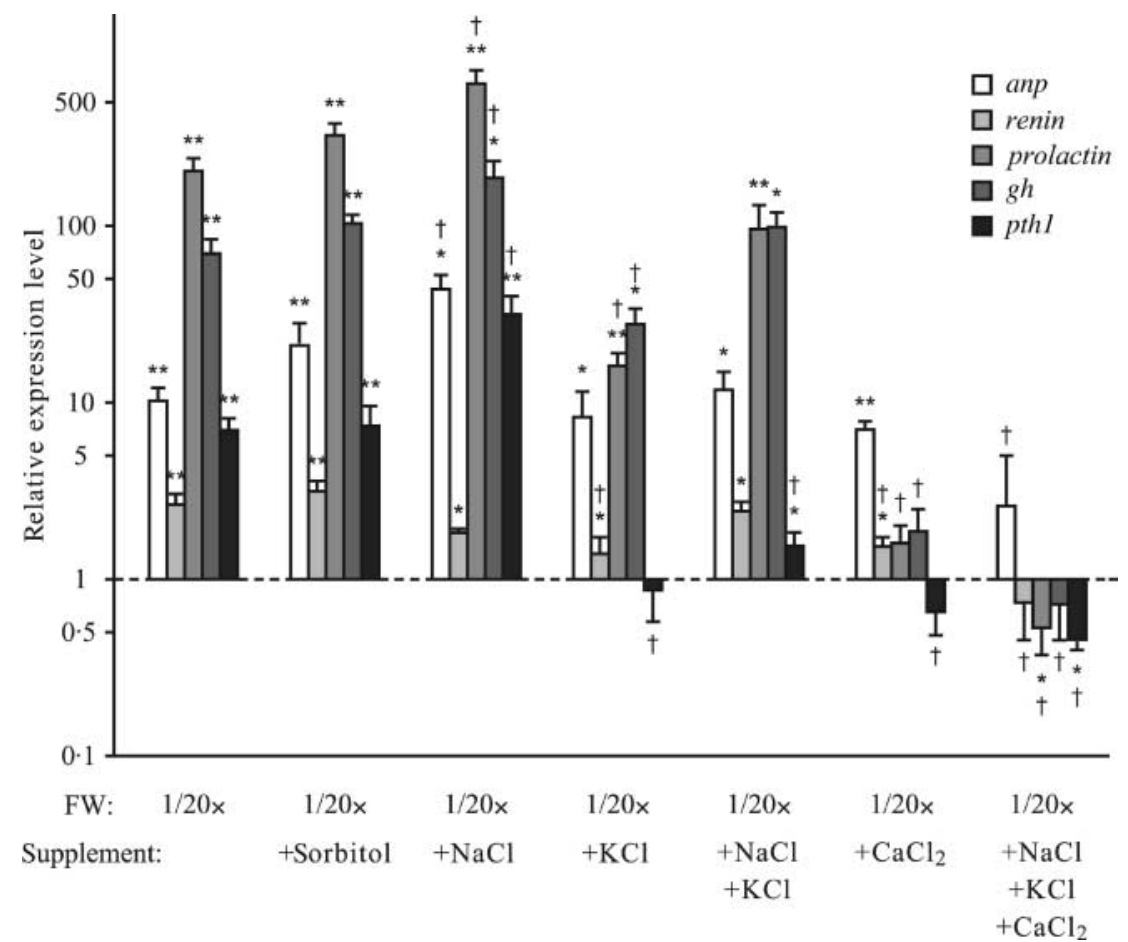

Figure 7 Expression level of endocrine genes in zebrafish larvae cultured in $1 / 20 \times \mathrm{FW}$ with a variety of supplements. Expression level of anp, renin, prolactin, gh, and pth1 was measured in zebrafish larvae cultured for 6 days ( $24 \mathrm{hpf}$ to $7 \mathrm{dpf}$ ) in $1 / 20 \times \mathrm{FW}$ with a variety of supplements (see Materials and Methods, and Table 1). The expression level of each gene obtained from replicate experiments $(n \geq 3)$ was normalized, calibrated and represented as described in Fig. 4. Asterisks and cross indicate a significant difference from the expression level in $1 \times \mathrm{FW}$ and $1 / 20 \times \mathrm{FW}$ respectively, as evaluated by a Mann-Whitney $U$-test, $\left({ }^{* *} P<0 \cdot 01,{ }^{*} P<0 \cdot 05,{ }^{+} P<0 \cdot 05\right)$.

and mammals likely reflect the relationship between blood volume and plasma $\mathrm{Na}^{+}$control. In mammals, volume control is usually in the same direction as plasma $\mathrm{Na}^{+}$ control, as mentioned above. In teleosts, however, the direction of volume control is opposite of plasma $\mathrm{Na}^{+}$ control. For example, in freshwater, hypervolemia and hyponatremia is the result of the influx of excess water and loss of $\mathrm{Na}^{+}$according to the osmotic gradient. In further diluted salinity conditions, i.e. $1 / 20 \times \mathrm{FW}$, hypervolemia and hyponatremia would be more extreme. We speculate that anp expression in $1 / 20 \times \mathrm{FW}$ may increase to respond to severe hypervolemia and promote excretion of excess water, similar to ANP function in mammals, while the increase in renin expression may be a response to the severe hyponatremia leading to $\mathrm{Na}^{+}$absorption as in mammals. The expression of anp and renin in $1 / 20 \times \mathrm{FW}$ supplemented with $\mathrm{NaCl}$ supports this hypothesis. In $1 / 20 \times \mathrm{FW}$ with $\mathrm{NaCl}$, zebrafish larvae formed severe edema in the chest and abdomen, likely due to uncontrollable hypervolemia, and anp, but not renin, expression was further elevated when compared with expression in $1 / 20 \times \mathrm{FW}$ (Fig. 7, 1/20× FW with $\mathrm{NaCl}$ ), indicating that anp rather than renin responded to the severe hypervolemia. On the other hand, reduction of renin expression, though not significant, may be responding to the increase in $\mathrm{Na}^{+}$from $1 / 20 \times$ to $1 \times$ concentration. Thus, in zebrafish, ANP, and Renin/RAS may be the volume-regulating and $\mathrm{Na}^{+}$-regulating hormones during freshwater adaptation, respectively. However, this notion cannot be generalized in teleosts as it is evident that ANP is likely to be the $\mathrm{Na}^{+}$-regulating and seawater-adapting hormone in euryhaline eels (Takei \& Hirose 2002, Takei et al. 2006). The difference may be species specific, although further investigation in other teleosts, especially in stenohaline freshwater fish, will be required to clarify the action of ANP and Renin/RAS in freshwater adaptation.

Expression of prolactin was strongly induced in zebrafish cultured in $1 / 20 \times \mathrm{FW}$, which is consistent with the osmoregulatory function during freshwater adaptation observed in other teleost fish (Burden 1956, Pickford \& Phillips 1959, Horseman 1987, Manzon 2002). Surprisingly, like prolactin, $g h$ expression was also elevated in $1 / 20 \times \mathrm{FW}$, which is in contrast to the function of $\mathrm{GH}$ as seawateradapting hormone in some euryhaline teleosts (Smith 1956, Sakamoto et al. 1993). Possibly, GH functions differently in the stenohaline zebrafish than in the euryhaline teleosts. 
Alternatively, more GH may be required for larval growth including bone formation when $\mathrm{Ca}^{2+}$ availability is limited in $1 / 20 \times \mathrm{FW}$, leading to the higher expression level. Supporting this hypothesis, the expression level of $g h$ decreased upon addition of $\mathrm{Ca}^{2+}$ to $1 / 20 \times \mathrm{FW}$ (Fig. 7,1/ $20 \times \mathrm{FW}$ with $\mathrm{CaCl}_{2}$,).

We also observed a salinity-dependent expression of pth1. The expression level of pth 1 increased in $1 / 20 \times \mathrm{FW}$, but decreased in $100 \times$ FW (Fig. 4). Importantly, pth 1 expression returned to standard levels in $1 / 20 \times \mathrm{FW}$ supplemented with $\mathrm{CaCl}_{2}$ (Fig. 7, 1/20× FW with $\mathrm{CaCl}_{2}$,), indicating that $p$ th 1 expression depends on the external $\mathrm{Ca}^{2+}$ level. pth 1 regulation in zebrafish larvae is similar to regulation in mammals where $p$ th is induced by a decrease in $\mathrm{Ca}^{2+}$ level in the plasma (Jüppner et al. 2000). In zebrafish, which do not have parathyroid glands, pth1 is primarily expressed in the CNS (Hogan et al. 2005). In preliminary experiments, we observed an increase in pth 1 expression in the CNS in response to lower $\mathrm{Ca}^{2+}$ levels (K Hoshijima, unpublished observations). An interesting question for further investigation is whether the regulation of pth1 expression in the CNS is conserved with regulation in the parathyroid glands in mammals.

This study demonstrates that the zebrafish endocrine system can respond to environmental salinity. The small size ( $\sim 5 \mathrm{~mm}$ length at $7 \mathrm{dpf}$ ) of zebrafish larvae would restrict biochemical or physiological analyses; however, accessibility to genetic manipulation including loss of function analyses with antisense oligonucleotides should be a great advantage for the functional study of endocrine genes (McGonnell \& Fowkes 2006). A comprehensive profiling of gene expression would also be useful for discovery of genes involved in the endocrine system. In fact, we have completed a preliminary examination of gene expression profiles under different salinity conditions, and have successfully identified hundreds of genes, whose expression is regulated by the external salinity (K, Hoshijima, unpublished observations). Taken together with the observations presented here, these comparative studies with zebrafish larvae should significantly contribute to our understanding of the regulatory mechanism of the endocrine system in vertebrates.

\section{Acknowledgements}

We thank Dr Hidekazu Fukuda for technical assistant and Dr Lisa M Goering for copyediting the manuscript. This work was supported by Grants-in-Aid for Scientific Research (14104002, 17570003, and 18059010) from the Ministry of Education, Culture, Sport, Science and Technology of Japan (MEXT) and the 21st Century Center of Excellence (COE) Program of MEXT. The authors declare that there is no conflict of interest that would prejudice the impartiality of this scientific work.

\section{References}

Abbink W \& Flik G 2006 Parathyroid hormone-related protein in teleost fish. General and Comparative Endocrinology. In press.

Abbink W, Bevelander GS, Rotllant J, Canario AV \& Flik G 2004 Calcium handling in Sparus auratus: effects of water and dietary calcium levels on mineral composition, cortisol and PTHrP levels. Journal of Experimental Biology 207 4077-4084.

Berdougo E, Coleman H, Lee DH, Stainier DY \& Yelon D 2003 Mutation of weak atrium/atrial myosin heavy chain disrupts atrial function and influences ventricular morphogenesis in zebrafish. Development $\mathbf{1 3 0}$ 6121-6129.

Bole-Feysot C, Goffin V, Edery M, Binart N \& Kelly PA 1998 Prolactin (PRL) and its receptor: actions, signal transduction pathways and phenotypes observed in PRL receptor knockout mice. Endocrine Reviews 19 225-268.

Burden CE 1956 The failure of hypophysectomized Fundulus heteroclitus to survive in freshwater. Biological Bulletin 110 8-28.

Copp D 1969 In The Ultimobranchial Glands and Calcium Regulation, vol 2, pp 8-28. Eds W Hoar \& D Randall. New York: Academic Press Inc.

Esaki M, Hoshijima K, Kobayashi S, Fukuda H, Kawakami K \& Hirose S 2007 Visualization in zebrafish larvae of $\mathrm{Na}^{+}$uptake in mitochondriarich cells whose differentiation is dependent on foxi3a. American Journal of Physiology. Regulatory, Integrative and Comparative Physiology 292 R470-R480.

Evans DH, Piermarini PM \& Choe KP 2005 The multifunctional fish gill: dominant site of gas exchange, osmoregulation, acid-base regulation, and excretion of nitrogenous waste. Physiological Reviews 85 97-177.

Fuentes J, Figueiredo J, Power DM \& Canario AV 2006 Parathyroid hormone-related protein regulates intestinal calcium transport in sea bream (Sparus auratus). American Journal of Physiology. Regulatory, Integrative and Comparative Physiology 291 R1499-R1506.

Gensure RC, Ponugoti B, Gunes Y, Papasani MR, Lanske B, Bastepe M, Rubin DA \& Juppner H 2004 Identification and characterization of two parathyroid hormone-like molecules in zebrafish. Endocrinology 145 1634-1639.

Gerlo S, Davis JR, Mager DL \& Kooijman R 2006 Prolactin in man: a tale of two promoters. Bioessays 28 1051-1055.

Gomez RA, Lynch KR, Chevalier RL, Wilfong N, Everett A, Carey RM \& Peach MJ 1988 Renin and angiotensinogen gene expression in maturing rat kidney. American Journal of Physiology 254 F582-F587.

Goodrich ES 1930 Studies on the Structure and Development of Vertebrates. London: Macmillan and Co. Ltd.

Greenwell MG, Sherrill J \& Clayton LA 2003 Osmoregulation in fish. Mechanisms and clinical implications. Veterinary Clinics of North America. Exotic Animal Practice 6 169-189.

Guerreiro PM, Renfro JL, Power DM \& Canario AV 2007 The parathyroid hormone family of peptides: structure, tissue distribution, regulation, and potential functional roles in calcium and phosphate balance in fish. American Journal of Physiology. Regulatory, Integrative and Comparative Physiology 292 R679-R696.

Herzog W, Zeng X, Lele Z, Sonntag C, Ting JW, Chang CY \& Hammerschmidt M 2003 Adenohypophysis formation in the zebrafish and its dependence on sonic hedgehog. Developmental Biology 254 36-49.

Hogan BM, Danks JA, Layton JE, Hall NE, Heath JK \& Lieschke GJ 2005 Duplicate zebrafish pth genes are expressed along the lateral line and in the central nervous system during embryogenesis. Endocrinology 146 547-551.

Horseman ND 1987 Models of prolactin action in nonmammalian vertebrates. In Actions of Prolactin on Molecular Processes, pp 41-67. Ed. JA Rillema. Boca Raton, FL: CRC Press.

Hyman LH 1942 Comparative Vertebrate Anatomy. edn 2, Chicago: The University of Chicago Press.

Jones CA, Sigmund CD, McGowan RA, Kane-Haas CM \& Gross KW 1990 Expression of murine renin genes during fetal development. Molecular Endocrinology 4 375-383. 
Jüppner H, Gardella TJ, Brown EM, Kronenberg HM \& Potts JJT 2000 Parathyroid hormone and parathyroid hormone-related peptide in the regulation of calcium homeostasis and bone development. In Endocrinology, pp 969-998. Eds LJ DeGroot \& JL Jameson. Philadelphia: W.B. Saunders.

Kaplan SL 1999 Hormone regulation of growth and metabolic effects of growth hormone. In Hormone Control of Growth, pp 129-143. Ed. JL Kostyo. New York: Oxford University Press.

Kirschner LB 2004 The mechanism of sodium chloride uptake in hyperregulating aquatic animals. Journal of Experimental Biology 207 1439-1452.

Kopchick JJ 2001 Growth hormone. In Endocrinology, pp 389-404. Eds LJ Degroot \& JL Jameson. Philadelphia: Saunders.

Liang P, Jones CA, Bisgrove BW, Song L, Glenn ST, Yost HJ \& Gross KW 2004 Genomic characterization and expression analysis of the first nonmammalian renin genes from zebrafish and pufferfish. Physiological Genomics 16 314-322.

Liu NA, Liu Q, Wawrowsky K, Yang Z, Lin S \& Melmed S 2006 Prolactin receptor signaling mediates the osmotic response of embryonic zebrafish lactotrophs. Molecular Endocrinology 20 871-880.

Loretz CA \& Pollina C 2000 Natriuretic peptides in fish physiology. Comparative Biochemistry and Physiology. Part A, Molecular and Integrative Physiology 125 169-187.

Manzon LA 2002 The role of prolactin in fish osmoregulation: a review. General and Comparative Endocrinology 125 291-310.

McCormick SD 2001 Endocrine control of osmoregulation in teleost fish. American Zoologist 41 781-794.

McCormick SD \& Bradshaw D 2006 Hormonal control of salt and water balance in vertebrates. General and Comparative Endocrinology 147 3-8.

McGonnell IM \& Fowkes RC 2006 Fishing for gene function-endocrine modelling in the zebrafish. Journal of Endocrinology 189 425-439.

Novak AE \& Ribera AB 2003 Immunocytochemistry as a tool for zebrafish developmental neurobiology. Methods in Cell Science 25 79-83.

Okabe M \& Graham A 2004 The origin of the parathyroid gland. PNAS 101 17716-17719.

Pickford GE \& Phillips JG 1959 Prolactin, a factor in promoting survival of hypophysectomized killifish in fresh water. Science 130 454-455.

Randall D, Burggren W \& French K 2002 Gas exchange and acid-base balance. In Eckert Animal Physiology, pp 525-578. edn 5, W H Freeman \& Co. Ltd.: New York.

Riddle O, Bates BW \& Dykshorn SW 1933 The preparation, identification and assay of prolactin - a hormone of the anterior pituitary. American Journal of Physiology 105 191-200.
Robertson JL 1993 The Renin-Angiotensin System. London: Gower Medical. Ruskoaho H 1992 Atrial natriuretic peptide: synthesis, release, and metabolism. Pharmacological Reviews 44 479-602.

Sakamoto T \& McCormick SD 2006 Prolactin and growth hormone in fish osmoregulation. General and Comparative Endocrinology 147 24-30.

Sakamoto T, McCormick SD \& Hirano T 1993 Osmoregulatory actions of growth hormone and its mode of action in salmoids: a review. Fish Physiology and Biochemistry 11 155-164.

Smith DCW 1956 The role of the endocrine organs in the salinity tolerance of trount. Memoirs of the Society for Endocrinology 5 83-101.

Takei Y \& Hirose S 2002 The natriuretic peptide system in eels: a key endocrine system for euryhalinity? American Journal of Physiology. Regulatory, Integrative and Comparative Physiology 282 R940-R951.

Takei Y \& Loretz CA 2005 Endocrinology. In The Physiology of Fishes, edn 3 , pp 271-318. Eds DH Evans \& JB Claiborne. Boca Raton, FL: CRC Press.

Takei Y, Kawakoshi A, Tsukada T, Yuge S, Ogoshi M, Inoue K, Hyodo S, Bannai H \& Miyano S 2006 Contribution of comparative fish studies to general endocrinology: structure and function of some osmoregulatory hormones. Journal of Experimental Zoology. Part A, Comparative Experimental Biology 305 787-798.

Tsukada T \& Takei Y 2006 Integrative approach to osmoregulatory action of atrial natriuretic peptide in seawater eels. General and Comparative Endocrinology 147 31-38.

Tsukada T, Rankin JC \& Takei Y 2005 Involvement of drinking and intestinal sodium absorption in hyponatremic effect of atrial natriuretic peptide in seawater eels. Zoological Science 22 77-85.

Westerfield M 1995 The Zebrafish Book: A Guide to the Laboratory Use of Zebrafish (Danio rerio). edn 3, Eugene: University of Oregon Press.

Zhu B \& Herbert J 1996 Central antagonism of atrial natriuretic peptides on behavioral and hormonal responses to angiotensin II: mapping with c-fos. Brain Research 734 55-60.

Received in final form 28 March 2007

Accepted 2 April 2007

Made available online as an Accepted Preprint 3 April 2007 